\title{
A Comparison of Pre- and Post-Cataloging Authority Control
}

\section{Karen E. Greever}

\begin{abstract}
As librarians at Ball State University Libraries prepared to implement the authority control module of its automated system, little information about the dependability of the module or its effectiveness as compared to the active system of providing authority control was available. The head of cataloging decided that it would be advisable to compare the effectiveness of the pre-cataloging authority control procedures in place with the post-cataloging authority control procedures that could be provided through the NOTIS reports. The two systems would be run concurrently during the test period. To test the effectiveness of each form of authority control, the Authority Control Librarian compared the number and type of established headings for which local authority records would be added using the pre-cataloging procedures to the number and type of established headings for which local authority records would be added using the report system. The test, as expected, revealed that in most respects the post-cataloging authority control procedures provide as much or more in the way of authority control than the front-end procedures, and that their uses reduce redundancy and increase efficiency.
\end{abstract}

I

library literature, many issues concerning authority control, including its usefulness or lack thereof, whether to do it at all, how much to do, and when to do it, have been discussed at length (see, for example, Younger 1995). However, as librarians at Ball State University Libraries prepared to implement the authority control module of the automated system (Kirby 1989), little information about the dependability of the module or its effectiveness as compared to the current system of providing authority control was

available. Librarians at Texas A\&M University chose to implement the same system without questioning its effectiveness (Halverson, Gomez, and Marner 1992), as did librarians at Auburn University, who planned carefully for implementation and for retrospective conversion of the paper authority file (Goldman and Smith 1989). Goldman and Havens (1990) provided statistics on increased efficiency with the implementation of automated authority control, but did not consider reliability. At Ball State, the new head of Cataloging

KAREN E. GreEver (00kegreever@bsu.edu) is Authority Control/Catalog Management Librarian at the Bracken Library, Ball State University, Muncie, Indiana. The author wishes to acknowledge the assistance and support of Suzan K. Burks, Head of Cataloging Services, and Brenda Wilkinson, Technical Cataloging Assistant. Manuscript received July 8, 1996; accepted for publication September 24, 1996 . 
Services had arrived from a library where authority control was done at the bibliographic utility level and where the local automated system did not always perform as advertised. She believed that the use of technology in the authority control process could result in overall performance improvement and was supportive of the implementation; however, she suggested that a verification of the new system's reliability would be helpful in subsequent evaluation of performance. To allay the concerns of the head of Cataloging and to provide data to the library administration, the head of Cataloging and the Authority Control Librarian decided to test the module.

The local environment will be described first, including the system of providing authority control prior to full cataloging of items, i.e., pre-cataloging authority control, and the problems that developed with it. Next, the test that was conducted to satisfy questions about the system will be described, followed by the results of the test, conclusions, and finally issues regarding implementation.

\section{Local ENVIRONMENT}

Ball State University Libraries have holdings of approximately 1.1 million titles. In $1995,17,321$ monographs were cataloged using the OCLC, Online Computer Library Center, Inc., bibliographic database as the bibliographic utility. Of those titles, $65 \%$ had Library of Congress (LC) copy, $30 \%$ member copy, and $5 \%$ required original records. In addition, 2,479 nonprint titles were cataloged. Currently, our new cataloging records are tapeloaded weekly. We load government documents records monthly and average one tapeload of records for major microform sets per year. We use an Innovative Interfaces system for Serials and Acquisitions. In 1990, we began using NOTIS Library Management System for our online catalog. We loaded authority records from a vendor cleanup of our database in 1991, but did not implement any of the NOTIS authority control programs until 1994. This delay was due in part to personnel changes in the key positions of head of Cataloging
Services and Authority Control Librarian.

Technical Services at Ball State consists of three units: Acquisitions, Educational Resources Technical Services (ERTS), and Cataloging Services. ERTS consists of 7 staff members and 3 professionals who perform cataloging, bibliographic maintenance, and physical processing for nonprint materials. Cataloging Services consists of 15 staff members and 6 professionals who perform monograph and serial cataloging, bibliographic maintenance, authority control, binding, and physical processing. The Authority Control section within Cataloging Services consists of one full-time staff member, several student assistants, and one professional, who also heads the Catalog Management section. For the most part, copy cataloging is performed by Technical Cataloging Assistants (TCAs). Original and locked records are done by catalogers, who also catalog the member copy for more complex titles and foreign-language materials.

\section{Pre-Cataloging authority Control}

Authority control had been performed at Ball State during the initial stages of cataloging even after the tapeload of retrospective authority records in 1991. Typically, Authority Control and Catalog Management TCAs searched for records in OCLC's bibliographic and authority databases, with the exception of topical subject headings. If the TCAs found conflicts between the headings in the authority record and the bibliographic record, or if there were cross-references to the heading in question, a printout was made of the authority record and the printout was attached to the bibliographic record printout. If an authority record matched the heading on the bibliographic record but there were no cross-references on the authority record, no printout was made. If it was necessary for a cataloger to establish a new heading (because there was no corresponding authority record in OCLC for that heading even though the heading occurred on a bibliographic record), a workform for that heading was attached to the 
bibliographic record. Typically, local authority records were created when there was a perceived need for crossreferences (e.g., compound surnames, variant forms of names, and subordinate corporate bodies) or when there was a need for explanatory notes. The final decision to create a local authority record was left to the individual cataloger's discretion. Using Library of Congress Subject Headings ( $L C S H)$, catalogers also verified topical subject headings on all non-LC copy. In ERTS, both bibliographic and authority searching were typically performed by the individual cataloging the title.

After the item was cataloged and the records linked, the printouts for the bibliographic records and the authority records were forwarded to Authority Control. Students working in the Authority Control section exported the authority records from OCLC. Other students input the locally established headings into NOTIS. A TCA reviewed all of the authority records added to NOTIS, deleting duplicate authority records as necessary. This TCA then modified the authority record to reflect the holdings in the database. The Serials Section, using the same methods, had the responsibility for maintaining series authority records. These procedures were used initially to build the authority file and to compensate for the time lag between the vendor clean-up and the loading of the authority records. They were not intended to continue indefinitely.

\section{Problem}

Over the course of three years, the use of these pre-cataloging authority control procedures resulted in an increase in the percentage of duplicate authority records to approximately $40 \%$ of all exported authority records, as estimated by library staff. This duplication resulted in a number of inefficiencies. First, staff wasted time following pre-cataloging procedures searching for authority records on OCLC that were already in the local system, searching on OCLC for authority records to be exported that would later be identified as duplicates, searching NOTIS for duplicate authority records, and deleting the duplicate local authority records. Second, the costs associated with printing authority records during pre-cataloging were also wasteful. Third, the library incurred OCLC charges for the export of duplicate records. Finally, it was costly to store deleted duplicate records in NOTIS. Moreover, the Authority Control section was unable to keep current with the heavy workload, including the management and storage of hundreds of printouts of bibliographic and authority records arriving weekly. All of the Cataloging staff recognized the duplication of efforts and the waste of resources. This was the situation that greeted the new head of Cataloging in late 1993.

The front-end authority control procedures could have been modified to reduce the duplication of authority records, but because the NOTIS system offered programs to assist with the authority control process, any modification of front-end procedures was seen as an interim measure at best. In consultation with the head of Technical Services and with input from the Authority Control Librarian, the head of Cataloging decided that it would be advisable to compare the effectiveness of the pre-cataloging authority control procedures in place with the post-cataloging authority control procedures that could be provided through the NOTIS reports. The two systems would be run concurrently during the test period. This would allow time for staff to become familiar with the reports, to establish the reliability and accuracy of the reports, and to gather data to convince and reassure both staff and administration of the wisdom of implementation.

Before describing the methodology of the test, a brief characterization of the NOTIS New Headings Report is beneficial. Also known as the "first time use" report in other local systems, this report, which is the cornerstone of ongoing authority control, compares headings currently in the local NOTIS bibliographic database with those headings present at a previous time, e.g., the previous week. It then lists all the headings that are new to the database in a report (see figure 1). 


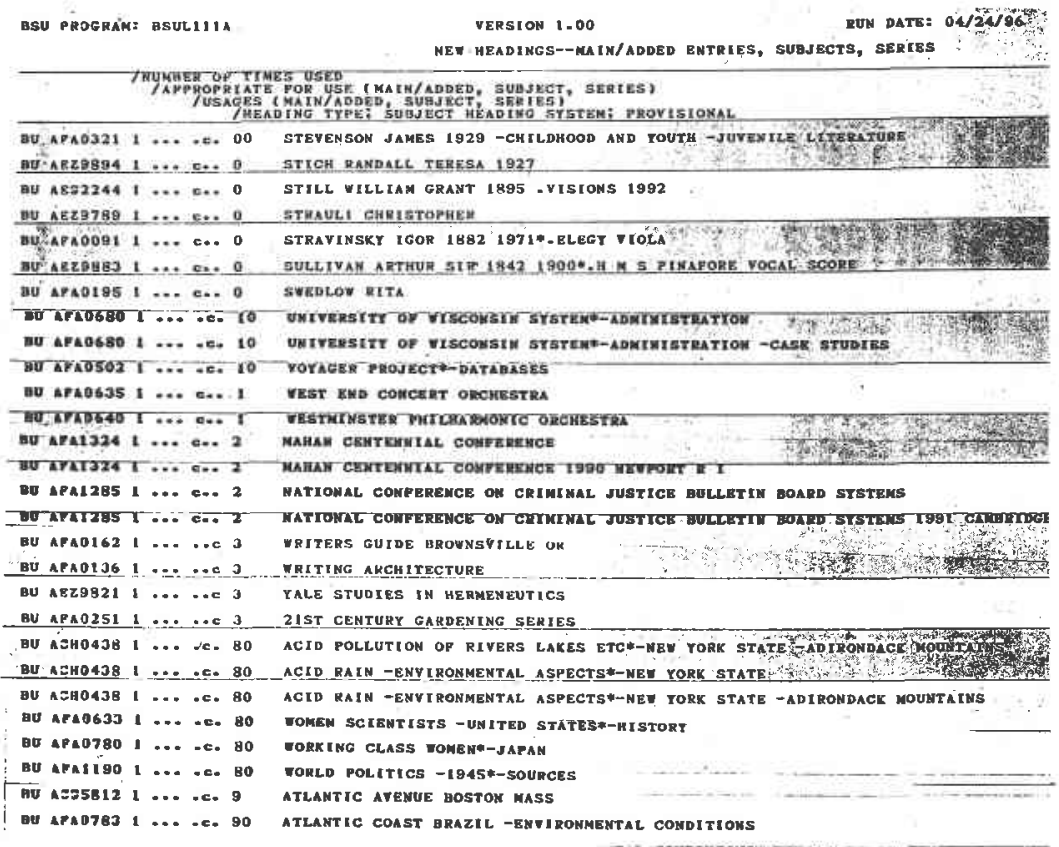

Figure 1.

Although the library's bibliographic database was loaded in 1990 and its authority records in 1991, the use of the New Headings Report did not begin until October 1994. Due to the long gap between the initial database load and the implementation of the New Headings Report, a large database of headings had been created for which the headings were precluded from this reporting process, because the report is produced when new bibliographic records are added to the database. Therefore, we began our use of this report with headings entered in October 1994.

\section{METHODOLOGY}

To test the effectiveness of each form of authority control, the Authority Control Librarian compared the number and type of established headings for which local authority records would be created using the pre-cataloging procedures to the number and type of established headings for which local authority records would be added using the report system. With the pre-cataloging practices, authority records were only added to the local file when there were cross-references for personal names, corporate names, and conferences in the OCLC record, or when cross-references were added locally either to the existing OCLC record or to a new authority record. For subject headings, authority records were also added to the local file for all subject headings as well as for subject-subdivision headings. This latter practice of adding local authority records for all subject-subdivision combinations was discontinued, however, prior to this investigation. These existing criteria for when to add authority records to the local file continued as the guidelines during the test. Only headings requiring locally created authority records were compared in this study because the number of new authority records imported from OCLC remains the same once the deduping process takes place, regardless of the method of authority control.

Working with the New Headings Re- 
port, the Authority Control staff exported all available authority records in OCLC corresponding to the headings on the report into NOTIS. The Authority Control Librarian examined all of the headings on each report, kept a tally of the headings that required the addition of cross-references, and counted the headings that therefore required a local authority record in NOTIS, according to the pre-cataloging practices discussed above. Then the Authority Control Librarian examined the cataloging printouts (bibliographic records with attached authority records and local workforms) for the corresponding period and tallied the cross-references added to existing authority records and the local authority records created by catalogers. Pre-cataloging heading totals, as represented in the printouts, were then compared by heading type to the totals compiled from the reports.

The headings that were examined include those found in the $100,110,111$, $700,710,711$, and $6 \mathrm{XX}$ fields. Series and uniform title headings, specifically the $130,240,4 \mathrm{XX}$, and $8 \mathrm{XX}$ fields, and $7 \mathrm{XX}$ subfield $t$, were not included in this comparison because the assumption from the outset of the test was that this authority work would continue to be done on the front end.

Because they had not been under authority control previously, headings on records for government documents were not initially considered part of the investigation. However, it became clear during the examination of the New Headings Report that headings on records for government documents formed a significant subset of headings requiring local authority work, so separate totals were recorded for these headings. Beginning in October 1994, 6 reports and the corresponding printouts were examined, covering the period from October to December. Approximately 7,700 bibliographic records were added to the database during this period, including 2,300 records for government documents.

\section{RESULTS}

The total number of local authority records created was 548. For records that were part of the regular authority control workflow using the New Headings Report, but exclusive of government documents, local authority records were created for 250 headings. One hundred thirteen of these $(45 \%)$, however, were not detected using the current front-end authority control procedures. Primarily, these undetected headings were from member copy and original cataloging records. In figure 2 , the number of local authority records added from the printouts and the reports is shown along with the subset of government document headings. During the test period, government documents records came under authority control for the first time. Two hundred ninety-eight local authority records were created for headings from document records, accounting for over half of the total number of locally created authority records. A summary of the results is provided in table 1. A comparison of the number of headings added using the printouts and reports and subdivided by heading type is provided in figure 3 .

Results of the cross-reference comparison are also presented in table 1 , followed by a comparison of the number of headings detected from the printouts but that were not found on the reports. In this category of "Headings missed on reports," the 10 undetected headings are most likely the result of errors in local processing of the first report received.

\section{Conclustons}

The percentage of locally established headings detected using the reports was substantially higher than the headings detected using the front-end approach. This difference may be explained by the fact that the old system introduced more variation and inconsistencies in decision making about creating local authority records because more people were making these decisions. During the examination of the reports, the Authority Control Librarian alone made judgments about the need for local authority records for all headings, which allowed for greater consistency in adhering to the criteria governing creation of local authority records. 


\section{Total Number of Headings \\ By Source}

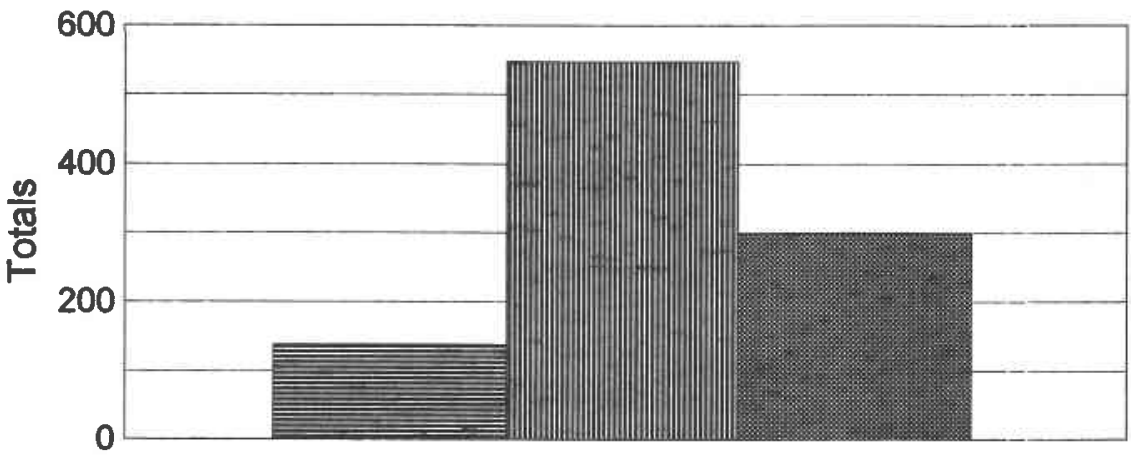

Source of Headings

Printouts

Gov Docs from Reports

Figure 2. Total Number of Headings by Source

\section{Total Number of Headings}

\section{By Heading Type}

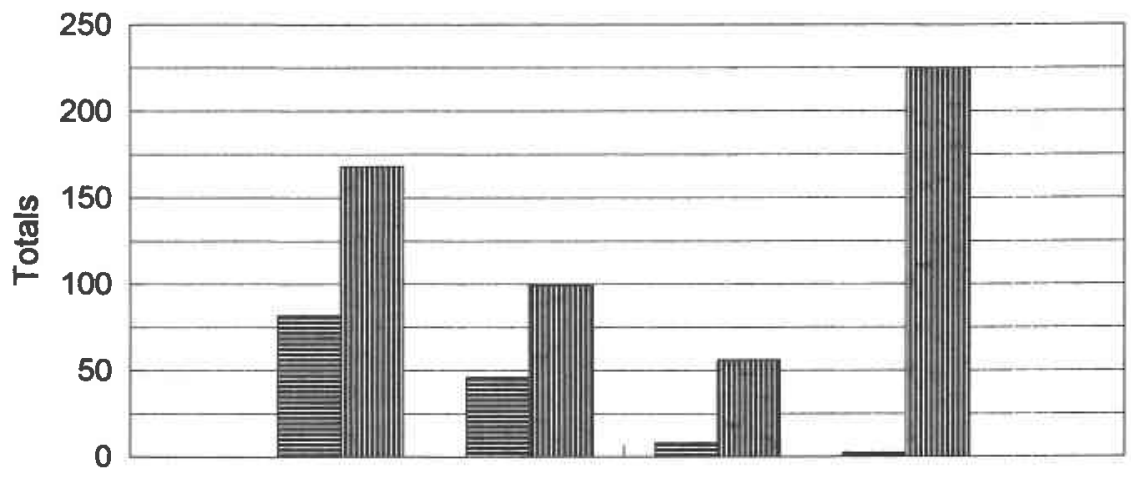

Names Corporates Conferences Subjects Heading types

圆Printouts 
TABLE 1

SUMMARY RESULTS FOR LOCALLY ESTABLISHED AUTHORITY RECORDS REPORT/PRINTOUT COMPARISON BY HEADING TYPE

\begin{tabular}{llccc}
\hline \hline Heading Type & Source & $\begin{array}{c}\text { Locally } \\
\text { Cataloged }\end{array}$ & $\begin{array}{c}\text { Gov Doc } \\
\text { Tapeload }\end{array}$ & $\begin{array}{c}\text { Total-Local } \\
\text { Authorities }\end{array}$ \\
\hline Names & Printouts & 82 & 0 & 82 \\
Corporate & Reports & 109 & 59 & 168 \\
Conference & Printouts & 46 & 0 & 46 \\
& Reports & 72 & 27 & 99 \\
Subject & Printouts & 8 & 0 & 8 \\
& Reports & 13 & 43 & 56 \\
Total headings & Printouts & 2 & 0 & 2 \\
& Reports & 56 & 169 & 225 \\
X-refs & Printouts & 137 & 0 & 137 \\
& Reports & 251 & 298 & 549 \\
Missed on Report & Printouts & 226 & 0 & 226 \\
& Reports & 109 & 114 & 223 \\
& Printout & 10 & N/A & 10 \\
\hline
\end{tabular}

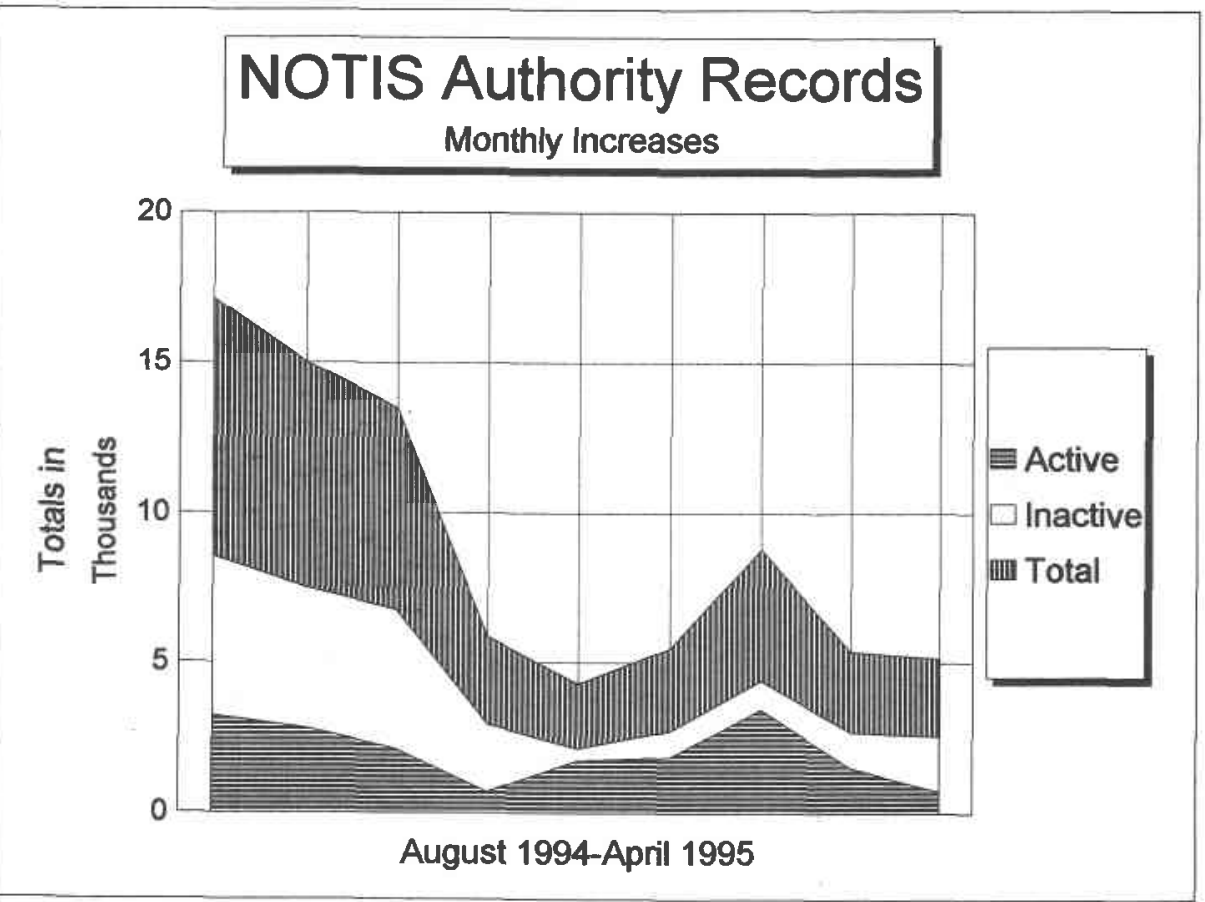

Figure 4. NOTIS Authority Records Monthly Increases 
TABLE 2

NOTIS AUTHORITY RECORDS: MONTHLY TOTALS AUGUST 1994-APRIL 1995

\begin{tabular}{lcccrrrrrr}
\hline \hline & Aug. & Sept & Oct. & Nov* & \multicolumn{1}{c}{ Dec. } & \multicolumn{1}{c}{ Jan. } & Feb. & March & April \\
\hline New & 3,219 & 2,804 & 2,119 & 706 & 1,752 & 1,863 & 3,461 & 1,518 & 728 \\
Deleted & 5,346 & 4,703 & 4,626 & 2,227 & 397 & 882 & 938 & 1,168 & 1,844 \\
Total & 8,565 & 7,507 & 6,745 & 2,933 & 2,149 & 2,745 & 4,399 & 2,686 & 2,572 \\
\hline
\end{tabular}

'Initiation of Post-Cataloging Authority Control test.

The number of cross-references detected through the reports compared to the printouts was similar. This may have been because under the old system, catalogers may not have forwarded authority records when they did not perceive a need for cross-references. The number of new authority records added to the database increased during the trial. We were pleased to see that the number of records exported from OCLC decreased significantly, most likely due to the elimination of the exporting of duplicate headings (see figure 4).

Even though these procedures were new, the Authority Control staff was able not only to keep up with processing the authority control reports, but also to process the backlog of authority control printouts that had accumulated using the older methods. In addition to regaining and maintaining currency, the use of the New Headings Report greatly reduced the redundancy inherent in earlier authority control procedures. Although the postcataloging authority control system has proven to be very efficient, the intense analysis required to process these reports is very taxing, in part because of the physical demands of spending extended periods of time at a computer terminal and also because of the mental exertion of carefully examining authority records and bibliographic records for inconsistencies, conflicts, and errors. This has been exacerbated because only one individual has performed these duties. Also, determining when cross-references should be added to imported authority records has required supplementary training.

The Cumulative Record Total Report generated by our Automation Department also provides information that reveals the savings due to the implementation of post-cataloging authority control (see table 2). In the November column of the table, the initial impact of post-cataloging authority control is indicated by a substantial decrease $(56 \%)$ in the total number of authority records-both those newly added to the database as well as those recently deleted. This decrease in large part reflects the reduction in duplicate authority records, which had been previously estimated to be around $40 \%$. Under the new procedures, fewer duplicates were added to the database, so fewer needed to be deleted.

Even though both methods of authority control were used during the investigation period, continued savings were realized because Authority Control has relied primarily on the reports to manage current workflow. Additional savings were indicated by the decrease in OCLC exporting charges over the same period (see

TABLE 3

OCLC EXPORT CHARGES

AUGUST 1994-APRIL 1995

\begin{tabular}{lccccccccc}
\hline & Aug & Sept & Oct. & Nov $^{\circ}$ & Dec & Jan. & Feb. & March & April \\
\hline Export Charges $(\$)$ & 434 & 450 & 381 & 191 & 195 & 243 & 269 & 256 & 199 \\
\hline
\end{tabular}

'Initiation of Post-Cataloging Authority Control test. 


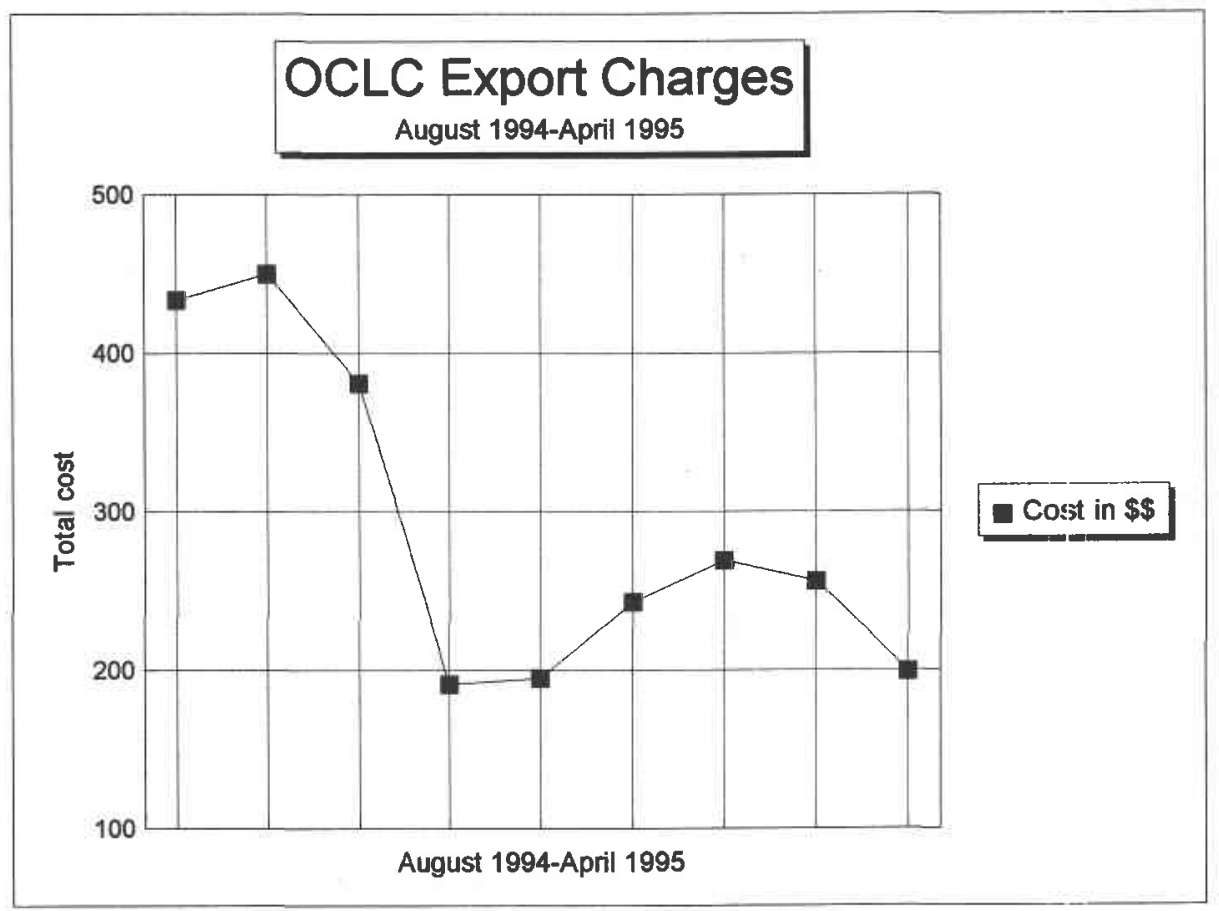

Figure 5. Decrease in OCLC Export Charges

table 3). Export charges decreased during and subsequent to the test despite additional activity that resulted from 3 new facets of authority control: (1) the processing of the Conflict and Error reports; (2) the authority work generated by a retrospective government documents cataloging project; and (3) the impact of all government documents being subject to authority control for the first time (see figure 5).

The reduction of duplicate authority records could have been accomplished by a modification of existing front-end authority control procedures, i.e., searching NOTIS for existing authority records prior to exporting records from OCLC. However, that modification would still have necessitated the redundancy of searching NOTIS manually, which is exactly what the New Headings Report is designed to do automatically. Consequently, this was not deemed to be a viable alternative.

As mentioned above, government documents received attention in the area of authority control for the first time since the inception of the tapeloading of government documents records at Ball State. In the past, the library itself had been unable to provide authority control for specially purchased tapeloads such as government documents and major microform products. Based on the success of the post-cataloging authority control process upon the government documents records, it is evident that any tape purchased and loaded by the library would receive adequate authority control easily accommodated by the post-cataloging procedures. Since the test, separate New Headings Reports of 300 and 800 pages have been provided for two tapeloads of major microform sets.

\section{IMPLEMENTATION OF NEW Procedures}

Given these results, the decision to implement was quickly made. The head of Cataloging and the Authority Control Librarian devised preliminary procedures and 
policies for implementation. These drafts were reviewed first by the professional librarians. After further revisions, the results of the test and the new policies and procedures were presented to the staff for comments and questions.

The head of Cataloging Services and the Authority Control Librarian reviewed local policies to determine which headings would require authority records in the local system. The decision was made to continue to export all authority records found in OCLC (both full and partial matches), and to create local authority records for headings requiring crossreferences, headings added to bibliographic records by local catalogers, and headings on new or locked records. The decision about which OCLC authority records to import and when local authority records would be required was based both on the automated system and on cataloging distinctions that would be easy to understand and remember. We decided that differentiating between types of OCLC authority records, e.g., those with and without cross-references, was not useful in our situation (and would be confusing for the students doing the bulk of the exporting). We decided to accept the authority work done by other libraries whether or not an actual authority record existed in OCLC. Thus we would not add local authority records for headings on OCLC member copy unless there was a perceived need for cross-references. However, for headings for which we were responsible, i.e., original cataloging, we wanted a way to indicate that proper authority work had been done by a cataloger regardless of whether cross-references were required. This required that local authority records be made for those headings. It became apparent after working with the authority control module that any other local authority records that lacked crossreferences or notes would serve no purpose in the online catalog. In terms of staff use, these authority records were either confusing or ignored, so this type of local authority record was eliminated.

The new procedures mandated that catalogers accept the form of all name and subject headings on LC and member copy. Corrections to the form are made during the review of the New Headings Report. However, catalogers are still responsible for subject analysis and determining whether a particular subject heading on the bibliographic record is justified. For new and locked records, all headings are verified during the cataloging process. Authority work for series and uniform titles continues to be performed during the cataloging process. There has not been any debate about the decision for uniform titles, but the possibility of using the New Headings Report to control series headings will be re-examined in the future.

In addition to the currency gained with the use of the New Headings Report, the ability to provide authority control for government documents and other tapeloads, and the time freed up for other authority control projects, there were also significant gains in cataloging productivity for LC copy. This was a benefit that was not anticipated when the decision to implement was made. One year after implementing post-cataloging authority control, the average number of books with LC copy cataloged per hour by the TCAs in Cataloging Services increased by 1.05 . This has allowed more time for special projects and for handling a greater variety of tasks.

\section{Concluding Remarks}

With post-cataloging authority control in place, it is easy for catalogers and TCAs to forget the situations (series and uniform titles) in which they are still required to verify and create authority records. Currently one staff member is doing the majority of work on the New Headings Report, which is rather arduous, although she is glad to be free of the printouts. The post-cataloging system and the New Headings Report are not yet well understood by all catalogers and TCAs, underscoring the need for effective follow-up and communication about the details of the new system. In part because of this lack of understanding, some have had trouble letting go of old work habits. After years of being trained to create "perfect" records and to be skeptical of the work of others, catalogers are now being told to accept and trust not only the cataloging done 
at other institutions but also the ability of the machine to identify headings to be reviewed for authority control. This study has demonstrated that the local system will produce a list of new headings that the authority control unit can then review to determine where authority records are needed.

In the end, the greatest benefits of the implementation are the reliability of the system-produced list of headings and the increased efficiency gained from postcataloging authority control that has provided people with the time to perform the more complex tasks and to focus on the judgments that machines cannot.

\section{Works CITED}

Goldman, Helen, and Carolyn Havens. 1990. Authority control efficiency increase: NO-
TIS online authority and merged headings. Cataloging and clessification quarterly 12 , no. 2: $27-45$.

Goldman, Helen, and David M. Smith. 1989. Name authority in a NOTIS environment-Auburn University Libraries. Cataloging \& classification quarterly 9 , no. 3: $121-31$.

Halverson, Jacque A., Joni Gomez, and Jonathan C. Marner. 1992. Creation and implementation of an automated authority section at the Texas A\&M University Library. Cataloging \& classification quarterly 15, no. 3: 57-68.

Kirby, Roberta F. 1989. Authority control in NOTIS. Cataloging \& classification quarterly 9, no. 3: 115-19.

Younger, Jennifer. 1995. After Cutter: Authority control in the twenty-first century. $\mathrm{Li}$ brary resources of technical services 39 : $133-41$.

\section{It takes VIZION to research the world.}

\section{Perfect for students and professionals-anyone serious about researching.}

VIZION offers a "Windowing" $\mathrm{Z3} 39.50$ client that's the quick and easy way to research on-line databases.

With VIZION you:

- Never need to learn different interfaces

- Search multiple databases girnulraneoush

- Create search histories to re-execute searchrstrategies easily

- Click on hypertext for related searches

No other software offers VIZION's ability-to store, organize and bookmark destinations with such ease and power. Plus, VIZION supports Telnet, FTP, Web browsers, Gopher and most DOS and Windows ${ }^{\mathrm{TM}}$ operating systems.

Order now and research the world!

$$
\text { Just } \$ 94.95
$$

Call toll free: 1-800-242-2233 Email: sales@sirsi.com Web site: http://www.sirsi.com

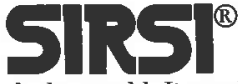

You need to reach the world. It needs to reach you. ${ }^{\mathrm{TM}}$ Windows is a trademark of Microsoft Corporation. 